\title{
Outcomes in females hospitalised with community-acquired pneumonia are worse
} than in males

\author{
Forest W. Arnold*, Timothy L. Wiemken*,\#, Paula Peyrani*, Mehdi Mirsaeidi* and \\ Julio A. Ramirez* for the Community Acquired Pneumonia Organization (CAPO) \\ Study Group
}

ABSTRACT: There is little recent information on sex-specific outcomes of patients with community-acquired pneumonia (CAP). The objective of this study was to determine whether female sex is associated with better clinical outcomes in hospitalised patients with CAP.

A secondary analysis was conducted by the Community Acquired Pneumonia Organization regarding male and female patients with CAP from 80 hospitals in 17 countries from June 1, 2001 to August 2, 2011. Outcomes were time to clinical stability, length of stay and in-hospital and 28day mortality. Propensity-adjusted, multivariate regression models were used to predict the probability of occurrence of each of the study outcomes.

There were 6718 patients in this study, of whom $40 \%$ were female. The adjusted hazard ratio (HR) for time to clinical stability was 0.91 (95\% $\mathrm{Cl} 0.85-0.97 ; p=0.005)$. The adjusted HR for length of stay was $0.94(95 \% \mathrm{Cl} 0.88-1.01 ; \mathrm{p}=0.089)$. The adjusted risk ratio for in-hospital mortality was 1.04 (95\% Cl 0.86-1.24; $p=0.717$ ), and for 28-day mortality was 1.15 (95\% Cl 1.02-1.30; $p=0.018)$.

This study demonstrates that the epidemiology of CAP may be changing, and that females have worse outcomes for CAP than males. They are more likely to take longer to reach clinical stability, have longer hospital stays and are $15 \%$ more likely to have died after 28 days. Current pneumonia scoring systems may need to be revised regarding female mortality risk.

KEYWORDS: Community-acquired pneumonia, female sex, length of stay, mortality, outcomes, quality measures

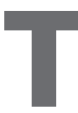
wo decades ago, sex-dependent differences in outcome and quality of care were acknowledged by the American Medical Association's Council on Ethical and Judicial Affairs as requiring prudent investigation [1]. This was followed by an emphasis in research needs about the respiratory health of females, but recent data are lacking.

Community-acquired pneumonia (CAP) is one of the most frequent infectious diseases and ranks as the fourth leading cause of death of females in the USA [2]. Studies with males and females combined have shown that mortality in CAP patients is associated with several independent risk factors, such as intensive care unit admission, advanced age, pleural effusion, increased time to first antimicrobial dose and the presence of comorbidities (e.g. anaemia, chronic renal failure and congestive heart failure), as well as sex $[3,4]$.
The first enquiry into sex and pneumonia started with hospital-acquired pneumonia (HAP). One study found that male patients had a greater incidence of HAP, and an increased length of stay (LOS) in the intensive care unit after trauma, but female patients who developed HAP demonstrated a higher mortality rate [5]. In another study, females were three times more likely to die than males with ventilator-associated pneumonia [6], but not in other studies [7, 8].

Two large studies using 1997 Medicare and Medicaid data described information regarding CAP outcomes and sex. It was shown in $>140000$ elderly, hospitalised, CAP patients that males had a greater mortality than females $(11.6 \%$ versus $9.8 \%, p<0.001)$ [9]. In another study, elderly males died more frequently than females in the subsequent year after hospitalisation for CAP, with the highest risk of death in the
AFFILIATIONS

*Division of Infectious Diseases, Dept of Medicine, School of Medicine, University of Louisville, Louisville, KY, and

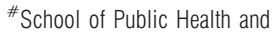
Information Sciences, Dept of Health Promotion and Behavior Sciences, University of Louisville, Louisville, KY, USA.

"For details for the CAPO Study Group, please see the Acknowledgements section.

CORRESPONDENCE

F.W. Arnold

Division of Infectious Diseases University of Louisville University of Louisville Hospital 501 E. Broadway

Suite 120

Louisville

KY 40292

USA

E-mail: F.Arnold@louisville.edu

Received:

March 152012

Accepted after revision:

June 302012

First published online:

July 262012 
first month after discharge $(44.8 \%$ versus $36.9 \%$, adjusted Kaplan-Meier $\mathrm{p} \leqslant 0.001)$ [10].

Enquiries into sex outcomes and CAP started after the first HAP studies addressed sex differences in outcome. The cost of treating CAP patients is significant, $\$ 10$ billion per year in the USA, with approximately $92 \%$ of this spent on hospital care [11]. Therefore, the decision to hospitalise patients for pneumonia is an important health economy issue. In an effort to improve decisions about hospitalisation, the pneumonia severity index (PSI) was introduced in 1997 as an accurate prognostic model of CAP to assess patients' risks [12]. The PSI was designed based on 21 study cohorts providing data (17 641 patients) showing that males die more than females, thus 10 points are subtracted from the PSI of a female patient [13]. The difference in points attributed to each sex using the PSI was accurate for the time period in which it was published; however, epidemiology has the potential to change over time. A new study evaluating the relationship between sex and outcome of patients with CAP is warranted.

We evaluated a large, multicentre, international cohort study of subjects with CAP to reassess the relationship between sex and poor outcomes in hospitalised patients with CAP.

\section{MATERIALS AND METHODS}

\section{Study design and study patients}

This was an international, retrospective study of adult patients hospitalised with CAP. Data was collected from 80 hospitals in 17 countries, between June 1, 2001 and August 2, 2011. In each participating centre, medical records of hospitalised patients with the diagnosis of CAP were reviewed. Charts were selected among all patients diagnosed with CAP at each institution. Antimicrobial regimens were not dictated by randomisation, nor were they recorded prospectively. Investigators completed a case report form that was transferred via a secure website to the Community Acquired Pneumonia Organization (CAPO) study headquarters at the University of Louisville in Louisville, KY, USA. A sample of the data collection form is available at: www.caposite.com. Validation of data quality was performed at the study centre before each case was entered into the CAPO database. The study was reviewed by the institutional review board and waived because this was a retrospective, observational study.

Records of all the patients enrolled in the study were reviewed for several factors. Demographic and comorbidity information included age, sex, world region, smoking status, nursing home residency status and comorbidities, including chronic obstructive pulmonary disease (COPD), congestive heart failure, coronary artery disease, hypertension, liver, renal or cerebrovascular diseases, diabetes mellitus, HIV infection and malignancy. Physical examination findings noted on admission included altered mental state and vital signs. Radiological findings reviewed were the number of involved lobes and the presence of cavitation or pleural effusion. Laboratory values from the day of admission included platelet count, leukocyte count, arterial blood gas analysis $(\mathrm{pH}$, arterial oxygen tension $\left(\mathrm{PaO}_{2}\right)$ and $\mathrm{PaO}_{2} /$ inspiratory oxygen fraction $\left(\mathrm{FIO}_{2}\right)$ ratio), serum sodium, serum creatinine, albumin, blood urea nitrogen (BUN) and hematocrit. The PSI [12] and CRB-65 (confusion, respiratory frequency $\geqslant 30$ breaths $\cdot \mathrm{min}^{-1}$, systolic blood pressure
$<90 \mathrm{mmHg}$ or diastolic blood pressure $\leqslant 60 \mathrm{mmHg}$ and age $\geqslant 65$ years) [14] were calculated, and microbiological information, when present, was also recorded.

\section{Study variable definitions}

CAP was defined as the presence of a new pulmonary infiltrate on chest radiograph at the time of hospitalisation associated with at least one of the following: 1 ) new or increased cough; 2) an abnormal temperature $\left(<35.6^{\circ} \mathrm{C}\right.$ or $\left.>37.8^{\circ} \mathrm{C}\right)$; 3$)$ an abnormal serum leukocyte count (leukocytosis, left shift or leukopenia defined by local laboratory values).

Hypotension was defined as a systolic blood pressure $<90 \mathrm{mmHg}$ or diastolic blood pressure $<60 \mathrm{mmHg}$. Alteration of gas exchange was defined as $\mathrm{PaO}_{2}<60 \mathrm{mmHg}, \mathrm{PaO}_{2} / \mathrm{FIO}_{2}$ ratio $<300$, or oxygen saturation $<90 \%$. Five processes of care were measured. Each subject was evaluated for blood cultures within $24 \mathrm{~h}$ of admission, antimicrobial administration within $8 \mathrm{~h}$ of admission, oxygenation status assessment and prior influenza and pneumococcal vaccine administration. CAPO regions are designated as USA/Canada, Europe, South America and Asia/Africa.

Time to clinical stability was calculated as the number of days from the date of admission to the date that the patient met clinical stability criteria. Time to clinical stability criteria were defined, as in the American Thoracic Society guidelines for $\mathrm{CAP}$, as all of the following: lack of fever for $\geqslant 8 \mathrm{~h}$, improving leukocytosis (decreased $\geqslant 10 \%$ from the previous day), tolerating oral intake and improved clinical signs (e.g. improved cough and shortness of breath) [15]. Criteria for clinical stability were evaluated daily during the first 7 days of hospitalisation. Patients who reached clinical stability within 7 days of admission were defined as being clinically improved. Length of stay (LOS) was calculated as the number of days from the date of admission (designated as day 0 ) to the date of discharge. Mortality was defined as death by any cause during hospitalisation (in-hospital mortality) and within 28 days (28day mortality). Time to clinical stability, LOS, in-hospital mortality and 28-day mortality were selected as outcomes.

\section{Statistical analyses}

Baseline patient characteristics and clinical outcomes of females and males were compared using Chi-squared or Fisher's exact tests for categorical variables and t-tests or Mann-Whitney U-tests for continuous variables. Sex differences in time to clinical stability and LOS were evaluated using Kaplan-Meier survival curves. Significant differences between the survival curves were analysed using the log-rank test.

To examine the impact of sex on in-hospital and 28-day mortality, propensity score adjustment methodologies were used [16]. Using a logistic regression model, a propensity score was created which included all the baseline patient characteristics shown in table 1 plus processes of care and need for intensive care. The propensity score was then used to adjust for differences in the study population using a Poisson regression model with robust error variance [17]. This methodology allowed us to obtain adjusted mortality (in-hospital mortality and 28-day mortality) risk ratios for those in each sex. The propensity score adjustment was also used to control for differences in the relationship between sex and time to clinical stability and LOS using Cox proportional hazards regression models. 


\begin{tabular}{|c|c|c|c|c|}
\hline \multirow{2}{*}{$\begin{array}{l}\text { TABLE } 1 \\
\text { Variable }\end{array}$} & \multicolumn{4}{|c|}{$\begin{array}{l}\text { Demographic, clinical, laboratory and } \\
\text { radiographic characteristics of } 6718 \text { patients with } \\
\text { community-acquired pneumonia }\end{array}$} \\
\hline & & Female & Male & p-value \\
\hline Subjects $n$ & & 2665 & 4053 & \\
\hline \multicolumn{5}{|c|}{ Demographics } \\
\hline Age years & & $64.8 \pm 21$ & $64.2 \pm 18.2$ & 0.2431 \\
\hline Nursing ho & he resident & $190(7.1)$ & $189(4.7)$ & $<0.001$ \\
\hline \multicolumn{5}{|c|}{ Comorbidities } \\
\hline COPD & & $469(17.6)$ & $1246(30.7)$ & $<0.001$ \\
\hline Congestive & neart failure & $455(17.1)$ & $704(17.4)$ & 0.7529 \\
\hline Cerebrovas & ular accident & $427(16)$ & $533(13.2)$ & 0.0010 \\
\hline Liver disea & & $106(4)$ & $266(6.6)$ & $<0.001$ \\
\hline Renal dise & & $211(7.9)$ & $475(11.7)$ & $<0.001$ \\
\hline Diabetes $\mathrm{n}$ & llitus & $402(15.1)$ & $785(19.4)$ & $<0.001$ \\
\hline \multicolumn{5}{|c|}{ Clinical signs and laboratory findings } \\
\hline Altered me & al status & $464(17.5)$ & 534 (13.2) & $<0.001$ \\
\hline Heart rate & 125 beats $\cdot \min ^{-1}$ & $364(13.7)$ & $483(11.9)$ & 0.0352 \\
\hline $\begin{array}{r}\text { Respiratory } \\
>30 \text { bre }\end{array}$ & $\begin{array}{l}\text { ate } \\
\mathrm{hs} \cdot \mathrm{min}^{-1}\end{array}$ & $572(22.5)$ & $741(19.1)$ & 0.0011 \\
\hline $\begin{array}{r}\text { Systolic blc } \\
<90 \mathrm{~mm}\end{array}$ & d pressure & $188(7.1)$ & $206(5.1)$ & 0.0008 \\
\hline Temperatu & $<35^{\circ} \mathrm{C}$ or $\geqslant 40^{\circ} \mathrm{C}$ & 229 (8.6) & $270(6.7)$ & 0.0031 \\
\hline $\mathrm{PaO}_{2}<60 \mathrm{r}$ & $\mathrm{mHg}$ & $1263(47.4)$ & $1974(48.7)$ & 0.2922 \\
\hline Blood urea & itrogen $\geqslant 30 \mathrm{mg} \cdot \mathrm{dL}^{-1}$ & $621(24.8)$ & $1193(30.7)$ & $<0.001$ \\
\hline Glucose $\geqslant$ & $50 \mathrm{mg} \cdot \mathrm{dL}^{-1}$ & $157(6.1)$ & $258(6.5)$ & 0.4883 \\
\hline Sodium $<$ & $30 \mathrm{mmol} \cdot \mathrm{L}^{-1}$ & 227 (8.5) & $336(8.3)$ & 0.7418 \\
\hline Hematocrit & $<30 \%$ & $293(11)$ & $350(8.6)$ & 0.0013 \\
\hline \multicolumn{5}{|c|}{ Radiological findings } \\
\hline Cavitary les & & $5(0.2)$ & $19(0.5)$ & 0.0588 \\
\hline Multilobar i & filtrates & $371(13.9)$ & $502(12.4)$ & 0.0671 \\
\hline \multicolumn{5}{|c|}{ Processes of care } \\
\hline Blood cultu & es obtained & $1759(66)$ & $2928(72)$ & $<0.001$ \\
\hline Antibiotics & ithin $8 \mathrm{~h}$ & $1818(78)$ & $2813(78)$ & 0.5698 \\
\hline Oxygenatic & assessed $^{\#}$ & 2616 (98) & 3998 (99) & 0.1177 \\
\hline Prior pneur & ococcal vaccine & $400(15)$ & $740(18)$ & $<0.001$ \\
\hline Prior influe & za vaccine & $381(14)$ & $663(16)$ & 0.0225 \\
\hline
\end{tabular}

Data are presented as mean \pm SD or $n(\%)$, unless otherwise stated. COPD chronic obstructive pulmonary disease; $\mathrm{PaO}_{2}$ : arterial oxygen tension \#: oxygenation data was not available for 769 subjects.

A p-value $\leqslant 0.05$ was considered to be statistically significant in all analyses. SAS v9.3 (SAS Inc., Cary, NC, USA) and MedCalc v12.0 (MedCalc Software, Mariakerke, Belgium) were used for all analyses.

\section{RESULTS}

A total of 6718 patients were included in the study: 2665 females and 4053 males. The mean \pm SD age was $64.7 \pm$ 19.1 years (range 18-104 years) and 40\% were female. Among the 25 variables collected, seven of them were worse for females (nursing home residence, cerebrovascular accident, mental status changes, abnormal temperature, tachypnoea, abnormal systolic blood pressure and anaemia), while five of them were worse for males (COPD, liver disease, renal disease, diabetes mellitus and abnormal BUN) (table 1). Among the processes of care, blood cultures were obtained less often from females and fewer females had received a pneumococcal vaccine prior to admission (table 1 ). The severity of disease was statistically similar using CRB-65, but was worse for males when using the PSI. The mean PSI for females was $85.8 \pm 46.6$, and for males was $94.7 \pm 45.7(\mathrm{p} \leqslant 0.001)$ (table 2$)$. The mean PSI for females without 10 points removed from their score was $94.7 \pm 48.8$ (online supplementary fig. E1) A pathogen was identified in 2204 patients. Streptococcus pneumoniae was the most common pathogen in both sexes. The most common pathogens are shown in table 3. Incidentally, among the 92 patients with Pseudomonas, only 11 were from a nursing home. The pneumonia unadjusted outcome results stratified by sex are shown in table 4, in which each outcome was worse for females. The number of females varied in each region: USA/ Canada: 603 (30\%); Europe: 1213 (42\%); South America: 804 (46\%); and Asia/Africa: 45 (61\%).

The analysis for time to clinical stability showed that females were less likely than males to reach clinical stability on any given day up to day 7 after admission. There was a difference in the Kaplan-Meier curves for each sex $(\mathrm{p}<0.001)$ (fig. 1). The adjusted hazard ratio (HR) for time to clinical stability was 0.91 (95\% CI 0.85-0.97; $\mathrm{p}=0.005$ ). The unadjusted analysis for LOS showed that females were less likely than males to be discharged from the hospital on any given day up to day 14 after admission. A difference between the Kaplan-Meier curves was detected ( $\mathrm{p}=0.006$ ) (fig. 2$)$, but the adjusted HR for LOS was 0.94 (95\% CI 0.88-1.01; $\mathrm{p}=0.089)$.

The proportion of patients who died while in the hospital was higher for females (10.8\%) than for males (9.3\%; $\mathrm{p}=0.041)$, but the adjusted risk ratio (RR) for in-hospital mortality was not

\begin{tabular}{|c|c|c|c|c|}
\hline TABLE 2 & \multicolumn{4}{|c|}{$\begin{array}{l}\text { The severity of disease for males and females } \\
\text { among } 6718 \text { patients with community-acquired } \\
\text { pneumonia }\end{array}$} \\
\hline \multicolumn{2}{|c|}{ Severity measure } & Female & Male & $\mathrm{p}$-value \\
\hline \multirow{2}{*}{\multicolumn{2}{|c|}{$\begin{array}{l}\text { Subjects n } \\
\text { CRB-65 }\end{array}$}} & 2665 & 4053 & \\
\hline & & & & \\
\hline \multicolumn{2}{|l|}{0} & $1831(69)$ & 2899 (72) & 0.20 \\
\hline \multicolumn{2}{|l|}{1} & $253(10)$ & $355(9)$ & \\
\hline \multicolumn{2}{|l|}{2} & 301 (11) & $415(10)$ & \\
\hline \multicolumn{2}{|l|}{3} & $190(7)$ & $284(7)$ & \\
\hline \multicolumn{2}{|l|}{4} & $69(3)$ & $80(2)$ & \\
\hline \multicolumn{2}{|l|}{5} & $10(0.4)$ & $15(0.4)$ & \\
\hline \multicolumn{5}{|c|}{ PSI risk class" } \\
\hline \multicolumn{2}{|l|}{1} & 308 (12) & $433(11)$ & $<0.001$ \\
\hline \multicolumn{2}{|l|}{ ॥ } & $588(22)$ & 471 (12) & \\
\hline \multicolumn{2}{|l|}{ III } & $493(19)$ & $807(20)$ & \\
\hline \multicolumn{2}{|l|}{ IV } & 836 (32) & 1509 (37) & \\
\hline \multicolumn{2}{|l|}{ V } & $414(16)$ & 805 (20) & \\
\hline \multicolumn{2}{|c|}{ ICU admission } & $280(11)$ & 489 (12) & 0.0497 \\
\hline
\end{tabular}

Data are presented as $\mathrm{n}(\%)$, unless otherwise stated. CRB-65: confusion respiratory frequency $\geqslant 30$ breaths $\cdot \mathrm{min}^{-1}$, systolic blood pressure $<90 \mathrm{mmHg}$ or diastolic blood pressure $\leqslant 60 \mathrm{mmHg}$ and age $\geqslant=65$ years; PSI: pneumonia severity index; ICU: intensive care unit. ${ }^{\#}$ : CRB-65 data missing for 16 subjects; ?: PSI data missing for 54 subjects. 


\begin{tabular}{|c|c|c|c|}
\hline & Female & Male & Total positive cultures \\
\hline Subjects & 836 & 1368 & \\
\hline Streptococcus pneumoniae & $356(43)$ & $514(38)$ & 870 \\
\hline Pandemic 2009 (H1N1) influenza $A^{\#}$ & $159(19)$ & $165(12)$ & 295 \\
\hline MRSA & $27(3)$ & $84(5)$ & 111 \\
\hline MSSA & 30 (4) & $54(4)$ & 84 \\
\hline Atypical pathogens & & & 153 \\
\hline Chlamydia spp. & $8(<1)$ & $10(<1)$ & 18 \\
\hline Legionella spp. & $25(3)$ & $65(5)$ & 90 \\
\hline Mycoplasma pneumoniae & $21(3)$ & $24(3)$ & 45 \\
\hline Moraxella catarrhalis & $18(2)$ & $26(2)$ & 44 \\
\hline Other $^{+}$ & 739 (88) & $1179(86)$ & 1918 \\
\hline
\end{tabular}

Data are presented as $\mathrm{n}$ or $\mathrm{n}(\%)$. Proportion is relative to the number of patients, not the number of specimens. Of the 2204 patients, 205 patients were co-infected, therefore, the sum of proportions in each region is $>100 \%$. MRSA: methicillin-resistant S. aureus MSSA: methicillin-sensitive S. aureus. ${ }^{*}$ : among 274 cases, 295 (93\%) were confirmed; ": all cases were C. pneumoniae except for one, which was C. psittaci; ${ }^{+}$: other organisms isolated were: Acinetobacter spp., adenovirus, Aspergillus spp., Candida spp., coagulase-negative Staphylococcus, Cryptococcus neoformans, Enterobacter spp., Enterococcus faecalis, untyped or H3N1 influenza, metapneumovirus, mixed anaerobic bacteria, nontuberculous bacteria, Paragonimus westermani, parainfluenza virus 1 and 4, Pneumocystis jiroveci; Proteus spp., Pseudomonas pseudomallei, respiratory syncytial virus A and B, rhinovirus/enterovirus, Salmonella spp., Serratia spp. and Streptococcus pyogenes; ${ }^{\text {s: }}$ sensitivity information was not available for 44 subjects.

statistically significant; adjusted RR 1.04 (95\% CI 0.86-1.24; $\mathrm{p}=0.717)$. The proportions of patients who died within 28 days were $26.0 \%$ for females and $21.4 \%$ for males $(\mathrm{p}<0.001)$. The result for this outcome was statistically significant when adjusted. The adjusted RR for 28-day mortality was 1.15 (95\% CI 1.02-1.30; $\mathrm{p}=0.018$ ).

\section{DISCUSSION}

This study shows that female sex was an independent predictor of clinical outcomes of CAP when examining hospitalised patients. Female patients were more likely to take longer to improve clinically when compared to male patients, and 28-day mortality was higher for female patients, with an absolute difference of $\sim 5 \%$. Adjusted outcomes were also worse for females, aside from LOS (which trended toward significance) and in-hospital mortality. The differences we observed between male and female patients conflict with those previously observed in CAP $[9,10]$. We may be witnessing an epidemiological shift that has occurred over recent decades, although little attention has been given to how males and females with CAP are managed; in other words there is a question of differences between the sexes in processes of care.

Including processes of care in the present study was important because one or more of them could have been a significant factor to explain the differences in outcomes between the two sexes. Obtaining blood cultures and having had a pneumococcal vaccine were performed in different proportions for each sex in the present study. Despite these two processes of care being quality measures of the National Hospital Quality Measures in USA, conflicting literature has been published in the last few years to support either one improving outcomes in

TABLE 4 Clinical outcomes by sex for 6718 patients with community-acquired pneumonia

\begin{tabular}{lccc} 
& Female & Male & p-value \\
\hline Subjects $\mathbf{n}$ & & & \\
Length of hospital stay days & 2665 & 4053 & \\
Time to clinical stability days & $8.9 \pm 4.2$ & $8.5 \pm 4.4$ & $<0.001$ \\
In-hospital mortality & $5.1 \pm 2.5$ & $4.8 \pm 2.6$ & $<0.001$ \\
28-day mortality & $287(10.8)$ & $375(9.3)$ & 0.0413 \\
\hline
\end{tabular}

Data are presented as mean \pm SD or $n(\%)$, unless otherwise stated. 


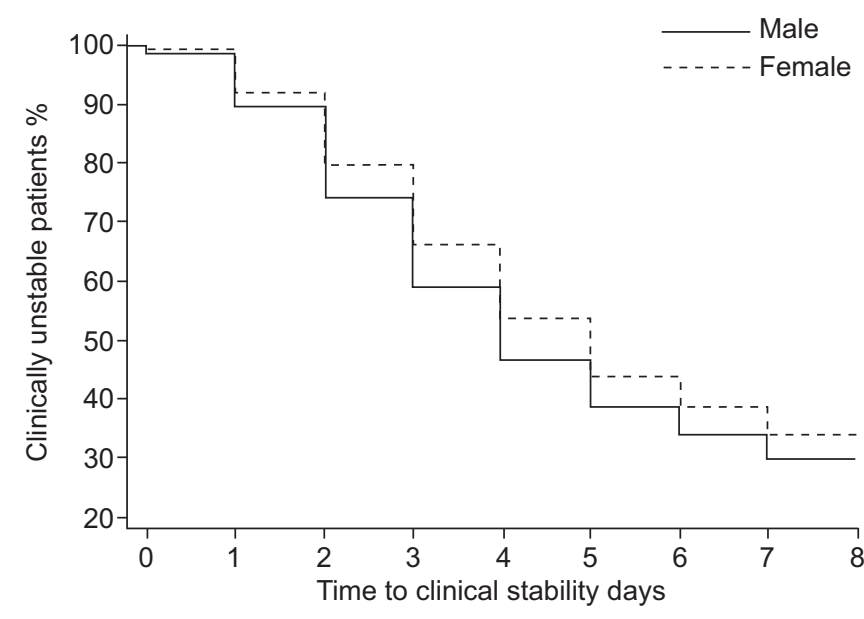

FIGURE 1. Kaplan-Meier curves for time to clinical stability among 2665 female and 4053 male patients with community-acquired pneumonia. $p<0.001$.

patients with CAP. A recent study of $>11000$ patients did not find a more frequent hospitalisation or a higher mortality among subjects who had been vaccinated prior to study entry [18]. Likewise, in a recent study regarding the effect of quality measures in CAP patients prior to administration of antimicrobials, none were found to be significant, including obtaining blood cultures [19]. Professional society guidelines in the USA now no longer recommend obtaining blood cultures in every patient admitted with CAP. Nevertheless, the differences in outcomes found in the present study were performed after adjusted analysis, including adjustment for the processes of care.

An implication of the present study is that the concept that female patients have a lower risk than males with CAP may need to be revised. Because female patients had worse outcomes in the present study, they may need to be hospitalised with a lower PSI score, or the PSI score needs to be revised. A certain number of points may not need to be subtracted from female scores, or may even need to be added for females in contrast to the current procedure of having 10 points subtracted from female scores. Furthermore, other current pneumonia scoring systems, such as the CRB-65, may need to adjust for sex [14]. In clinical studies, females would be represented more accurately and distributed according to real severity of disease; hence there would be fewer $\alpha$ - and $\beta$-errors.

Our study was limited by its retrospective nature, which means that there may have been selection bias. If all patients admitted for CAP were included, then that would have helped, but that was not the case. Furthermore, the patients that were enrolled were limited to the specialised type of patients seen by each principal investigator. The study was limited to the five processes of care that were reviewed. Other processes of care, such as whether to perform a special procedure (e.g. bronchoscopy or parapneumonic effusion drainage) or when to admit to an intensive care unit, were not available in the database and may have been significant. Although the proportions of comorbidities and severity of illness were controlled for statistically, it would have been ideal for these values to be equal between the sexes, thus obviating the need for adjustment. A prospective trial or a case-control study

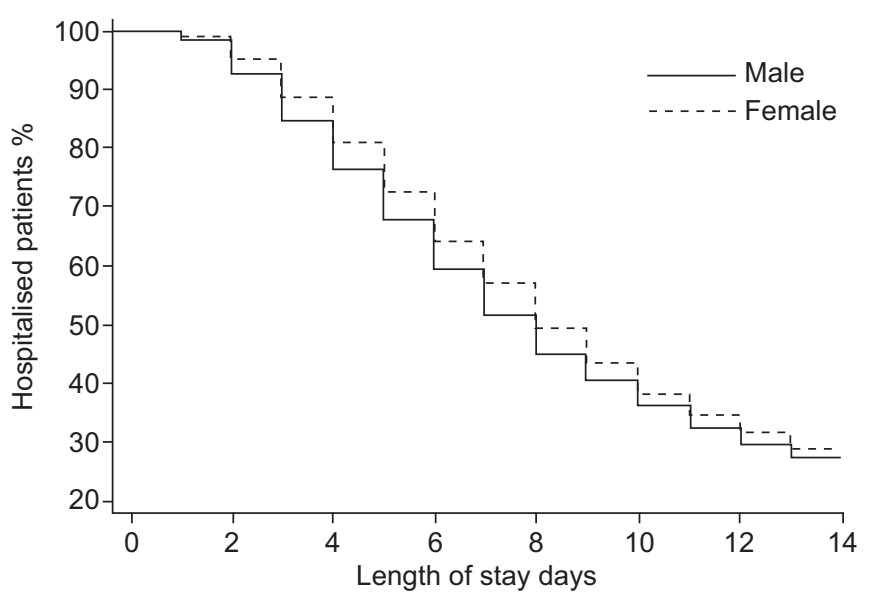

FIGURE 2. Kaplan-Meier curves for length of stay among 2665 female and 4053 male patients with community-acquired pneumonia. $p=0.006$.

could be designed to equalise the severity of disease in each group. A prospective, randomised controlled study would also control for confounding factors.

Despite these limitations, this study demonstrates several unique strengths. It is an international study including patients from multiple continents. It highlights an area that needs to be studied further to ensure that females are being attributed an accurate severity of illness when cared for clinically. The exclusion criteria were minimal, allowing the representation of patients to be close to what might be encountered in many areas of the world, thus increasing its generalisability. The present study includes nearly 7000 patients whose diagnoses of CAP were confirmed radiographically, as opposed to identification with diagnosis or billing codes.

In conclusion, this study shows that female patients have a higher risk of poor CAP outcomes than males during hospitalisation worldwide. They have a longer time to clinical stability, and higher 28-day mortality than males. Further research is needed to verify our findings prospectively. If epidemiology has changed and females with CAP truly have worse outcomes compared to males, as the data in this study demonstrate, then future research to revise current pneumonia scoring systems regarding higher female mortality risk is needed.

\section{STATEMENT OF INTEREST}

None declared.

\section{ACKNOWLEDGEMENTS}

The authors gratefully acknowledge the work of the CAPO investigators in building and maintaining the CAPO data set. USA: F. Arnold, D. Christensen, P. Peyrani and J. Ramirez (University of Louisville, Louisville, KY); R. Nakamatsu (Veterans Affairs Medical Center, Louisville, KY); K. Ayesu (Orlando Regional Medical Center, Orlando, FL); B. Ostrowsky (Montefiore Medical Center and Weiler Hospital, New York, NY); T. File Jr (Summa Health System, Akron, OH); S. Burdette (Greene Memorial Hospital, Xenia, OH); S. Blatt (Good Samaritan Hospital, Cincinnati, OH); M. Restrepo (University of Texas Health Science Center, San Antonio, TX); J. Bordon (Providence Hospital, Washington, DC); P. Gross (Hackensack University Medical Center, Hackensack, NJ). Canada: T. Marrie (University of Alberta Hospital, Sturgeon Community Hospital, Grey Nuns Hospital and Royal Alexandra Hospital, Edmonton); K. Weiss (Maisonneuve-Rosemont 
Hospital, University of Montreal, Montreal). Puerto Rico: R. Fernandez (Hospital Municipal de San Juan, San Juan). Andorra: J. Roig (Hospital Nostra Senyora de Meritxell, Escaldes). Germany: H. Lode (City Hospital E.v.Behring/Lungenklinik Heckeshorn, Berlin); T. Welte (Medizinische Hochschule Hannover, Hanover). Italy: F. Blasi and S. Aliberti (Instituto Malattie Respirattorio, University of Milan, Instituto di Recerca e Cura a Carattere Scientifico, Policlinico, Milan); R. Cosentini (Policlinico, Milan); D. Legnani (Ospedale L. Sacco, Milan); G. Cervi (Policlinico di Modena, Modena); P. Rossi (S. Maria della Misericordia, Udine). Spain: A. Torres (Instituto de Neumonologia y Cirugia Toracica, CIBER Enfermedades Respiratorias, Barcelona); D. Portela Ojales (Hospital Xeral-Cies, Vigo); M. Bodi (Hospital Universitario Joan XXIII, Tarragona); J. Porras (Hospital Sant Pau i Santa Tecla, Tarragona); J. Rello (Critical Care Department, Joan XXIII University Hospital, CIBER Enfermedades Respiratorias, University Rovira and Virgili, Tarragona); R. Menendez (Pneumology Service, Hospital Universitario La Fe, CIBER Enfermedades Respiratorias, Valencia). Switzerland: D. Stolz (Universitatsspital Basel, Basel). UK: J. Chalmers (Royal Infirmary of Edinburgh and Western General Hospital, Edinburgh); T. Fardon (Ninewells Hospital, Dundee). Argentina: G. Benchetrit (IDIM A. Lanari, Buenos Aires); E. Rodriguez (Hospital Espanol de La Plata, La Plata); J. Corral (Hospital Dr Oscar Alende, Mar del Plata); J. Gonzalez (Hospital Enrique Tornu, Buenos Aires); L. de Vedia (Hospital Francisco J. Muniz, Buenos Aires); G. Lopardo (Profesor Bernardo Houssay Hospital, Buenos Aires); C. Luna (Hospital de Clinicas, Buenos Aires); J. Martinez (Instituto Medico Platense, La Plata); L. Marzoratti (Sanatorio 9 de Julio, Tucuman); M. Rodriguez (Hospital Rodolfo Rossi, La Plata); A. Videla (Hospital Universitario Austral, Buenos Aires); F. Saavedra (Sanatorio Otamendi Miroli, Buenos Aires); H. Lopez (Centro de Infectología, Buenos Aires); M. Gnoni (Sanatorio Central EMHSA, Bueno Aires); J. Gonzalez (Hospital Enrique Tornu, Buenos). Chile: P. Jimenez (Hospital Clinico Regional, Santiago); P. Fernandez (Instituto Nacional del Torax, Santiago); M. Parada (Clinica las Condes, Santiago); A. Díaz Fuenzalida (Pontificia Universidad Católica de Chile, Santiago); R. Riquelme (Hospital de Puerto Montt, Puerto Montt); M. Barros (Hospital Carlos van Buren Hospital, Valpraiso). Guatemala: J. Manuel Luna (Hospital Nacional Roosevelt, Guatemala City). Panama: I. Toala (Complejo Hospitalario Dr Arnulfo Arias Madrid, Panama City). Paraguay: G. Arbo Oze de Morvil (Clinica San Roque y Centro Médico La Costa, Asuncion). Uruguay: G. Aiello (Maciel Hospital, Montevideo). Venezuela: F. Arteta (Hospital Luis Gomez Lopez-Ascardio, Barquisimeto); J. Delgado (Hospital Central Dr Urquinaona, Maracaibo); G. Levy (Hospital Universitario de Caracas, Caracas); L. Rivero (Hospital Central University Antonio M. Pineda, Barquisimeto); B. Rodriguez (Hospital IVSS Dr Domingo Guzman Lander, Barquisimeto); M. Perez Mirabal (Hospital Universitario de Los Andes, Merida). Philippines: M. Mateo (University of Santo Thomas Hospital, Manila); M. Mendoza (University of the Philippines and National Kidney and Transplant Institute, Manila). South Africa: C. Feldman (Johannesburg Hospital, Johannesburg).

\section{REFERENCES}

1 McMurray RJ, Clarke OW, Barrasso JA, et al. Gender disparities in clinical decision making. JAMA 1991; 266: 559-562.
2 Centers for Disease Control and Prevention. National Vital Statistics System Website. www.cdc.gov/nchs/nvss.htm Date last updated: December 4, 2012. Date last accessed October 6, 2011.

3 Fine MJ, Stone RA, Singer DE, et al. Processes and outcomes of care for patients with community-acquired pneumonia: results from the Pneumonia Patient Outcomes Research Team (PORT) Cohort Study. Arch Intern Med 1999; 159: 970-980.

4 Torres A, Menendez R. Enterobacteriaceae and Pseudomonas aeruginosa in community-acquired pneumonia: the reality after a decade of uncertainty? Eur Respir J 2010; 35: 473-474.

5 Napolitano LM, Greco ME, Rodriguez A, et al. Gender differences in adverse outcomes after blunt trauma. J Trauma 2001; 50: 274-280.

6 Combes A, Luyt CE, Fagon JY, et al. Early predictors for infection recurrence and death in patients with ventilator-associated pneumonia. Crit Care Med 2007; 35: 146-154.

7 Rello J, Rue M, Jubert P, et al. Survival in patients with nosocomial pneumonia. Crit Care Med 1997; 25: 1862-1867.

8 Singh N, Falestiny MN, Rogers P, et al. Pulmonary infiltrates in the surgical ICU. Chest 1998; 114: 1129-1136.

9 Kaplan V, Angus DC, Griffin MF, et al. Hospitalized communityacquired pneumonia in the elderly: age- and sex-related patterns of care and outcome in the United States. Am J Respir Crit Care Med 2002; 165: 766-772.

10 Kaplan V, Clermont G, Griffin MF, et al. Pneumonia: still the old man's friend? Arch Intern Med 2003; 163: 317-323.

11 Lave JR, Lin CJ, Fine MJ, et al. The cost of treating patients with community-acquired pneumonia. Semin Respir Crit Care Med 1999; 20: 189-197.

12 Fine MJ, Auble TE, Yealy DM, et al. A prediction rule to identify low-risk patients with community-acquired pneumonia. $N$ Engl J Med 1997; 336: 243-250.

13 Fine MJ, Smith MA, Carson CA, et al. Prognosis and outcomes of patients with community-acquired pneumonia: a meta-analysis. JAMA 1996; 275: 134-141.

14 Macfarlane J, Boswell T, Douglas G. BTS guidelines for management of community acquired pneumonia in adults - 2004 update http://www.brit-thoracic.org.uk/portals/0/clinical\%20information/ pneumonia/guidelines/macaprevisedapr04.pdf Date last accessed: October 8, 2011.

15 Niederman MS, Mandell LA, Anzueto A, et al. Guidelines for the management of adults with community-acquired pneumonia diagnosis, assessment of severity, antimicrobial therapy, and prevention. Am J Respir Crit Care Med 2001; 163: 1730-1754.

16 Imai $\mathrm{K}$, van Dyk DA. Causal inference with general treatment regimes: generalizing the propensity score. J Am Stat Assoc 2004; 99: 854-866.

17 Zou G. A modified poisson regression approach to prospective studies with binary data. Am J Epidemiol 2004; 159: 702-706.

18 Vila-Corcoles A, Ochoa-Gondar O, Lior C, et al. Protective effect of pneumococcal vaccine against death by pneumonia in elderly subjects. Eur Respir J 2005; 26: 1086-1091.

19 Lee JS, Primack BA, Mor MK, et al. Processes of care and outcomes for community-acquired pneumonia. Am J Med 2011; 124: 1175. 